\title{
Flexibility and posture assessment in relation to hamstring injury
}

\author{
L. Hennessy and A. W. S. Watson \\ Sports Injuries Research Centre, University of Limerick, Limerick, Ireland
}

\begin{abstract}
Posture and flexibility were assessed in 34 athletes. Subjects were divided into two groups: (1) a noninjured group that did not have a history of hamstring strain injury within the previous 12 months; (2) an injured group that had a history of hamstring strain within the previous 12 months. Ten postural components were assessed: head erectness; shoulder symmetry; spinal curvature; hip symmetry; foot and ankle alignment; knee hyperextension; upperback roundness; trunk erectness; abdomen protrusion; and lumbar lordosis. Hamstring flexibility was assessed in both legs. Results indicated no difference $(P>0.05)$ in flexibility between groups (mean(s.d.) of both legs was: noninjured $=77.1(9.3)^{\circ}$, injured $=$ 77.8(9.2) ${ }^{\circ}$. Also no difference $(P>0.05)$ was observed between the injured limb and the noninjured limb for injured subjects (injured $\operatorname{limb}=78.1(11.1)^{\circ}$, noninjured limb $=77.5(8.1)^{\circ}$. A significant difference $(P>0.01)$ between groups occurred in low back posture (lumbar lordosis). No other difference occurred in the remaining nine posture components between groups. Intercorrelation coefficients among posture components indicated that at best only $53 \%$ of common variance existed between any two components (head and shoulder components: $r=0.73$, $P<0.01)$. All other correlations indicated less than $40 \%$ common variance between components. The results of the study indicate that while differences in hamstring flexibility are not evident between injured and noninjured groups poorer low back posture was found in the injured group. Regular monitoring of posture in athletes is recommended.
\end{abstract}

Keywords: hamstring injury, posture, flexibility, field games, lumbar lordosis, contributory factors

An athlete's competitive preparations and aspirations are often compromised by injury. The average Irish athlete suffers the effects of sports injury for approximately 52 days per year ${ }^{1}$. Hamstring muscle strain is frequently a common injury in athletes ${ }^{1-3}$. Among the many factors reported to be associated with hamstring strain are poor flexibility and postural abnormalities ${ }^{4-7}$. However, only limited empirical data are available relating these particular factors to hamstring strain ${ }^{5,8}$.

Stephens and Reid ${ }^{9}$ found no difference between hamstring flexibility and history of injury. In that

Address for correspondence: Liam Hennessy, c/o Dr A. W. S. Watson, Sports Injuries Research Centre, University of Limerick,
Limerick, Ireland

(C) 1993 Butterworth-Heinemann Ltd 0306-3674/93/040243-04 study the sit and reach test was used to assess hamstring flexibility. As no differentiation between the injured and noninjured limbs can be made with the sit and reach test it is of limited value in assessing the relationship between hamstring strain and flexibility. Watson found that postural deviations were significantly higher in team players than in those who play other sports ${ }^{5}$. Further, groin strain and back injury were found to be more common in athletes with lumbar lordosis ${ }^{5}$. Although it is widely perceived that postural defects may predispose athletes to certain injuries ${ }^{4,10}$ there is a dearth of scientific evidence to support such a belief. Therefore, it was decided to examine the relationship between hamstring flexibility and history of injury in the hamstring muscle group. Additionally, the relationship between hamstring strain history and posture was investigated.

\section{Materials and methods}

The subjects for this study were 34 team players from rugby, hurling and Gaelic football. Subjects were divided into two groups. The control group consisted of 16 players who had not suffered from any hamstring strains during the preceding year. The experimental group consisted of players who had suffered hamstring strain on at least one occasion during the previous year. Subjects were informed as to the purpose of the study and written informed consent was obtained. Hamstring flexibility was measured using a custom made device employing a large protractor and a metre rule. The use of the device and the method of testing has been outlined previously ${ }^{4,10}$. Posture was assessed using the New York posture rating chart ${ }^{11}$. This chart was modified to include an assessment of hyperextension of the knees ${ }^{5}$ based on the scoring method used in the New York posture rating chart. Each subject stood in a normal upright position dressed only in swim trunks and with bare feet. Components 1-5 were assessed from a posterior aspect and components $6-10$ were assessed from a side view. Such a procedure has been recommended as the method of choice for this type of investigation ${ }^{5}$. In brief the components of posture examined were: (1) erectness of head; (2) shoulder symmetry; (3) spinal curvature (scoliosis); (4) hip symmetry; (5) foot and ankle alignment; (6) knee hyperextension; (7) upper back roundness; (8) trunk erectness; (9) abdomen protrusion; and (10) lumbar 
Flexibility and posture assessment: L. Hennessy and A. W. S. Watson

Table 1. Test-retest determinations

\begin{tabular}{llllr}
\hline Measurement & Test* & Retest* $^{*}$ & $\begin{array}{c}95 \% \\
\text { Confidence (\%) } \\
\text { limits }\end{array}$ & $\begin{array}{c}V \\
\end{array}$ \\
& & & & \\
\hline Hamstring flexibility & $67.4(8.0)$ & $68.5(7.1)$ & 7.2 & 3.2 \\
Posture rating score (total) & $65.0(9.5)$ & $65.4(9.7)$ & 6.7 & 1.9 \\
\hline
\end{tabular}

*Values are mean(s.d.); V, method error of variation

Table 2. Physical characteristics of injured and noninjured subjects

\begin{tabular}{lccc}
\hline Subjects & $\begin{array}{c}\text { Age } \\
(\text { years })\end{array}$ & $\begin{array}{c}\text { Height } \\
(\mathrm{cm})\end{array}$ & $\begin{array}{c}\text { Weight } \\
(\mathrm{kg})\end{array}$ \\
\hline Noninjured $(n=16)$ & $25.3(3.6)$ & $180(6.2)$ & $80.6(7.7)$ \\
Injured $(n=18)$ & $23.7(3.9)$ & $178(5.7)$ & $77.5(5.8)$
\end{tabular}

Values are mean(s.d.)

Table 3. Flexibility characteristics of injured and noninjured groups

\begin{tabular}{llc}
\hline Variable & \multicolumn{2}{c}{ Flexibility (degrees) } \\
\cline { 2 - 3 } & Noninjured & Injured \\
\hline Left leg & & $78.3(7.5)$ \\
Right leg & $75.9(9.7)$ & $77.3(11.5)$ \\
Injured leg & $78.3(9.4)$ & $78.1(11.1)$ \\
Noninjured leg & & $77.5(8.1)$ \\
Mean of left and right legs & $77.1(9.3)$ & $77.8(9.2)$ \\
\hline
\end{tabular}

Values are mean(s.d.) lordosis. Each component was scored on a continuous scale from 0 to 10 , where 0 was rated as poor, 5 rated as fair and 10 rated as good. Deviations from posture outlines related to these scores were scored in whole units. Posture components were assessed twice in one group $(n=18)$ to examine the test-retest reliability of the procedure.

Test-retest reliabilities for the measurements employed in this study are presented in Table 1. Both measurements indicate acceptable method error coefficients of variation ${ }^{12}$. Further, no systematic difference $(P>0.05)$ between means was found.

\section{Statistical analyses}

Unrelated $t$ tests were used to test for differences between the mean scores of the noninjured and the injured groups.

Additionally, a Pearson product moment correlation matrix was used to examine intercorrelations among the variables measured in this study. Because of the number of comparisons being made a significance level of $P<0.01$ was selected in order to avoid making a type 1 error. All analyses were carried out using the SPSS-X package ${ }^{13}$.

\section{Results}

Physical characteristics of the injured and noninjured groups are outlined in Table 2. No difference was found between groups in age, height and weight. Table 3 outlines the mean values of the groups for flexibility. No differences in flexibility were found between groups for either left or right legs, injured and noninjured legs within the injured group, and for mean flexibility of both left and right legs.

No relationship between flexibility and postural components was identified (Table 4). While significant correlations $(P<0.05)$ were found between several components of posture the variance accounted for was (for all except one relationship) less than $40 \%$.

Table 4. Pearson product moment intercorrelation matrix for flexibility and postural components

\begin{tabular}{|c|c|c|c|c|c|c|c|c|c|c|c|c|c|}
\hline \multirow[b]{2}{*}{ Variable } & \multicolumn{13}{|c|}{ Flexibility and posture component intercorrelations } \\
\hline & $\begin{array}{l}\text { Left } \\
\text { leg }\end{array}$ & $\begin{array}{l}\text { Right } \\
\text { leg }\end{array}$ & $\begin{array}{c}\text { Mean } \\
\text { left and } \\
\text { right }\end{array}$ & Head & Shoulder & Spine & Hip & Ankle & Knee & $\begin{array}{l}\text { Upper } \\
\text { back }\end{array}$ & Trunk & Abdomen & $\begin{array}{l}\text { Lumbar } \\
\text { lordosis }\end{array}$ \\
\hline Left leg & $1.00^{*}$ & $0.83^{*}$ & $0.94^{*}$ & -0.15 & -0.20 & -0.29 & -0.30 & -0.20 & -0.14 & -0.10 & -0.20 & -0.18 & -0.18 \\
\hline Right leg & $0.83^{*}$ & $1.00^{*}$ & $0.96^{*}$ & 0.02 & -0.11 & -0.25 & -0.04 & -0.19 & -0.16 & -0.13 & -0.14 & -0.15 & -0.02 \\
\hline Mean left and right & $0.94^{*}$ & $0.96^{*}$ & $1.000^{*}$ & -0.05 & -0.16 & -0.28 & -0.17 & -0.21 & -0.16 & -0.12 & -0.19 & -0.17 & -0.10 \\
\hline Head & -0.15 & 0.02 & -0.05 & $1.00^{*}$ & $0.73^{*}$ & 0.33 & 0.31 & 0.33 & 0.18 & 0.22 & $0.34 t$ & $0.48^{*}$ & $0.34 t$ \\
\hline Shoulder & -0.20 & -0.11 & -0.16 & $0.73^{*}$ & $1.00^{*}$ & $0.58^{*}$ & 0.31 & $0.38+$ & $0.38 t$ & $0.38 t$ & $0.49^{*}$ & $0.47^{*}$ & 0.13 \\
\hline Spine & -0.29 & -0.25 & -0.28 & 0.33 & $0.58^{*}$ & $1.00^{*}$ & $0.51^{*}$ & 0.28 & $0.35 t$ & $0.49^{*}$ & $0.40 t$ & 0.27 & 0.02 \\
\hline Hip & -0.31 & -0.04 & -0.17 & 0.31 & 0.31 & $0.51^{*}$ & $1.00^{*}$ & 0.22 & 0.27 & 0.32 & $0.37 t$ & 0.32 & 0.24 \\
\hline Ankle & -0.21 & -0.19 & -0.21 & $0.33 t$ & $0.38 t$ & 0.28 & 0.22 & $1.00^{*}$ & $0.46^{*}$ & $0.46^{*}$ & $0.35 t$ & 0.23 & 0.20 \\
\hline Knee & -0.14 & -0.16 & -0.16 & 0.18 & $0.38 t$ & $0.35 t$ & 0.27 & $0.46^{*}$ & $1.00^{*}$ & $0.45^{*}$ & $0.55^{*}$ & $0.41 t$ & $0.34+$ \\
\hline Upper back & -0.10 & -0.13 & -0.12 & 0.22 & $0.38 t$ & $0.49^{*}$ & 0.32 & $0.46^{*}$ & $0.45^{*}$ & $1.00^{*}$ & $0.64^{*}$ & $0.34 t$ & 0.19 \\
\hline Trunk & -0.24 & -0.14 & -0.19 & $0.34 t$ & $0.49^{*}$ & $0.40+$ & $0.37 t$ & $0.35 t$ & $0.55^{*}$ & $0.64^{*}$ & $1.00^{*}$ & $0.53^{*}$ & $0.51^{*}$ \\
\hline Abdomen & -0.18 & -0.15 & -0.17 & $0.48^{*}$ & $0.47^{*}$ & 0.27 & 0.32 & 0.23 & $0.41 t$ & $0.34 t$ & $0.54^{*}$ & $1.00^{*}$ & $0.67^{*}$ \\
\hline Lumbar lordosis & -0.18 & -0.02 & -0.10 & $0.34 t$ & 0.13 & 0.02 & 0.24 & 0.20 & $0.34 t$ & 0.19 & $0.51^{*}$ & $0.67^{*}$ & $1.00^{*}$ \\
\hline
\end{tabular}

${ }^{*} P \leqslant 0.01,+P \leqslant 0.05$ 


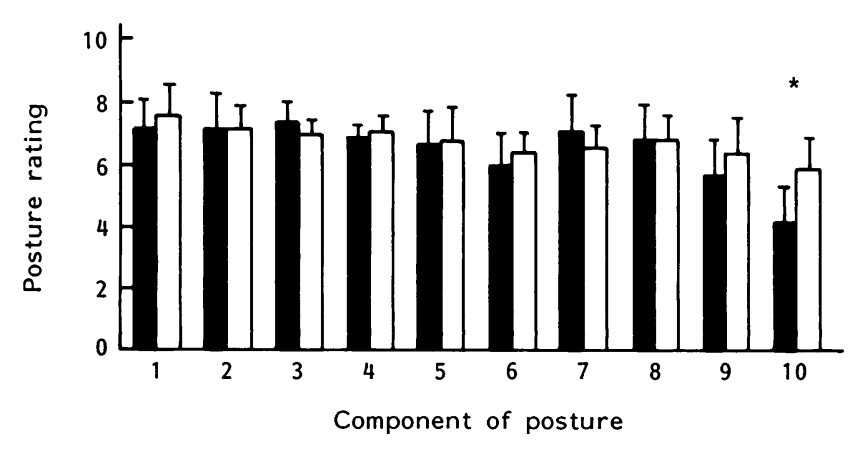

Figure 1. Score for components of posture for injured and noninjured groups. Values expressed are mean(s.d.). (1) Head erectness; (2) shoulder symmetry; (3) spinal curvature; (4) hip symmetry; (5) foot and ankle alignment; (6) knee hyperextension; (7) upper back roundness; (8) trunk erectness; (9) abdomen protrusion; (10) lumbar lordosis. *Injured versus noninjured players significantly different $(P<0.01)$. Injured players, $\square$; noninjured players, $\square$

Head and shoulder components of posture were found to share a common variance of $53 \%$.

No differences between groups were found in nine of the ten posture components examined (Figure 1). However, a significant difference $(P<0.01)$ was found in lumbar lordosis between groups. A greater deviation in lumbar posture was found in the injured group than in the control group (mean(s.d.) of 4.2(1.6) versus 5.9(1.4), respectively).

\section{Discussion}

The results of this investigation show that there is no difference in flexibility between subjects with a history of hamstring injury and subjects with no history of injury. This is in agreement with the findings of Stephens and Reid ${ }^{9}$. In that study the authors found no difference in flexibility as determined by the sit and reach test between football players with a history of hamstring injury and players who did not experience hamstring strains. While it is generally believed that athletes may be less flexible on the injured limb than on the contralateral limb ${ }^{7}$ the findings of the present study do not support this belief. The range of motion achieved by subjects in this study is similar to the range reported in pretraining in other athletes (mean(s.d.) $76.9(8.8)^{\circ}$ ) but less than the range of motion achieved after a period of training $\left(81.5(7.8)^{\circ}\right)$ for the same athletes ${ }^{14}$. Therefore, the levels of flexibility found in the subjects in the present study may be considered less than optimum. Other authors have noted a greater incidence of muscle strains in players with reduced flexibility ${ }^{3}$. However, this association does not imply that poor flexibility is the cause of muscle strain. Hilyer et al. ${ }^{15}$ have reported that a flexibility training programme had a beneficial effect on reducing the severity of joint injuries in a group of subjects but did not reduce the incidence of injury. However, other authors have noted that careful attention to stretching among other methods of training can reduce the number of primary and recurrent injuries in ath- letes ${ }^{2,3,16}$. Nevertheless, it is possible that following hamstring strain in the injured limb careful attention was given to frequent and progressive stretching by the subjects in this study. Subjects in the experimental group had all received treatment from a physiotherapist for hamstring injuries and this invariably included practical advice on the importance and methods of correct stretching procedures.

No relationship was found between components of posture and hamstring flexibility in the present study. Additionally, each posture component was found to be predominantly distinct. This is in agreement with the findings reported elsewhere ${ }^{5}$.

While it is difficult to determine the exact cause of sports injuries careful attention to correcting predisposing factors is recommended. Attention to improving flexibility is well recognized as an injury reducing method ${ }^{17}$ yet attention to the assessment and monitoring of postural deviations is less practised presumably because of the lack of a definitive relationship between posture and injury occurrence in the literature. The difference in the degree of lumbar lordosis between groups in the present study suggests an association between this postural deviation and hamstring strain. However, other authors believe that anatomic variations are risk factors for only a few individuals while functional abnormalities, such as muscle imbalance about a joint, poor strength and poor range of motion are more important risk factors ${ }^{18}$. Yet Muckle ${ }^{6}$ has previously associated lumbar spine abnormalities with hamstring strains and the findings of this study support that belief. Further, Watson ${ }^{5}$ found that the degree of lumbar lordosis increased during the course of two seasons in games players. Kicking and executing abdominal strengthening exercises with straight legs have been identified as possible contributory causes of lordosis ${ }^{5,19}$. The anatomical reason seems to be that the iliopsoas muscle group is primarily involved in kicking and straight leg raising or straight leg sit-up exercises and contributes to strengthening this muscle $^{10}$. Therefore, it is possible that certain athletic activities and training methods which exacerbate postural defects may also predispose the player to injury.

In summary, no differences between injured and noninjured subjects in hamstring flexibility were found. However, a difference in the postural component of lumbar lordosis was found between groups.

The findings of this study suggest that greater attention should be given to the regular assessment of posture in sports and subsequent prescriptive measures to correct noted deviations. Expertise in such assessment and the prescription of corrective exercises is essential in tackling this area. It is recommended that such procedures be carried out by appropriately trained personnel.

\section{References}

1 Watson AWS. Incidence and nature of sports injuries in Ireland: analysis of four types of sport. Am J Sports Med 1993; 21: 137-43.

2 Heiser TM, Weber J, Sullivan G, Clarke P, Jacobs $R$. Prophylaxis and management of hamstring muscle injuries in 
Flexibility and posture assessment: L. Hennessy and A. W. S. Watson

intercollegiate football players. Am J Sports Med 1984; 12: $368-70$.

3 Ekstrand J, Gillquist J. The avoidability of soccer injuries. Int J Sports Med 1983; 4: 124-8.

4 Watson AWS. Physical Fitness and Athletic Performance. London, UK: Longman, 1983.

5 Watson AWS. Posture and participation in sport. J Sports Med Phys Fitness 1983; 23: 231-9.

6 Muckle DS. Associated factors in recurrent groin and hamstring injuries. $\mathrm{Br}$ J Sports Med 1982; 16: 37-9.

7 Liemohn W. Factors related to hamstring strains. J Sports Med 1978; 18: 71-6.

8 Watson AWS. Lumbar lordosis and strain of the iliopsoas. $\mathrm{Br} \mathrm{J}$ Sports Med 1974; 8: 203-4.

9 Stephens D, Reid JG. Biomechanics of hamstring strains in sprinting events. Can J Sports Sci 1988; 13: 88.

10 Corbin CB, Lindsey R. Concepts of Physical Fitness with Laboratories. 6th ed. Dubuque, Iowa, USA: Wm. C. Brown, 1988: 105-6.

11 The New York Physical Fitness Test: A Manual for Teachers of PE. New York State Education Department (Division of Health, Physical Education and Recreation), New York, USA, 1958.
12 Sale DG. Testing Strength and Power. Physiological Testing of the High-Performance Athlete. 2nd ed. Champaign, Illinois, USA: Human Kinetics, 1991: 21-106.

13 SPSS-X User's Guide. 3rd ed. Chicago, Illinois, USA: Statistical Package for the Social Sciences, 1988.

14 Hennessy L, Watson AWS. Physical characteristics and physical fitness variables in Gaelic Athletic Association players. Sports Injuries Research Centre, University of Limerick, 1993.

15 Hilyer JC, Brown KC, Sirles AT, Peoples L. A flexibility intervention to reduce the incidence and severity of joint injuries among municipal firefighters. J Occup Med 1990; 32: 631-7.

16 Ekstrand J, Gillquist J. Soccer injuries and their mechanisms. A prospective study. Med Sci Sports Exerc 1983; 15: 267-70.

17 NSCA Round Table Discussion on Athletic Rehabilitation: Part 2. Nat Strength \& Cond Assoc J 1992; 14: 10-16.

18 O'Toole ML. Prevention and treatment of injuries to runners. Med Sci Sports Exerc 1992; 24: 9 (Suppl): S360-3.

19 Wheeler RH, Hooley AM. Physical Education for the Handicapped. Philadelphia, USA: Lea and Febiger, 1969.

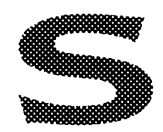

We offer a reprints service in respect of all articles in this journal.

Companies: an article featuring your product or a new application provides its readers with an independent authoritative comment. Reprints can be used by you to inform and edúcate your customers and staff about scientific or technical advances in subjects relevant to your

business. They are a cost-effective, ethical way of promoting your company and its products.

For a quotation on your reprint requirements, please contact:

The Reprints Department, Butterworth-Heinemann Ltd., Linacre House, Jordan Hill, Oxford, OX2 8DP. Tel: +44 (0)865 310366. Fax: +44 (O)865 314519

\begin{tabular}{llllllllll}
$B$ & $U$ & $T$ & $T$ & $E$ & $R$ & $W$ & $O R$ & $T$ & $H$ \\
\hline & $E$ & $I$ & $N$ & $E$ & $M$ & $A$ & $N$ & $N$
\end{tabular}

